ALPHA No 29 Diciembre 2009 (85-104)

ISSN 0716-4254

http://alpha.ulagos.cl

\title{
¿REESCRIBIENDO LA HISTORIA?: UNA PANORÁMICA DE LA FICCIÓN HISTÓRICA TELEVISIVA ESPAÑOLA RECIENTE ${ }^{1}$
}

Re-writing history?: an overview of recent Spanish television historical fiction

José Carlos Rueda Laffond*

Resumen

Este trabajo se dirige a replantear el papel de la ficción histórica en las televisiones nacionales españolas a través del análisis de varios programas. El autor estudia la producción de series de ficción histórica entre 2008-2009 y describe sus funciones para crear una imagen de la reciente historia española. El artículo pretende definir las características del género y el proceso de producción de significaciones culturales e históricas.

Palabras clave: España, historia reciente, televisión, series de ficción histórica, narrativas históricas, significaciones culturales.

Abstract

This paper aims to rethink the role of historical fiction in national Spanish television, through the analysis of various programmes. The author studies the production of historical fiction series between 2008-2009, and describes their functions to create a self-image of recent Spanish history. This article attemps to define this genre's characteristics and the process and the production of cultural and historical significations.

Key words: Spain, recent history, television, historical fiction series, historical narratives, cultural significations.

\section{EL PANORAMA DE LA FICCIÓN HISTÓRICA TELEVISIVA ESPAÑOLA}

A lo largo de los últimos meses se han multiplicado los contenidos de temática históricas en la televisión española. Además de las entregas ajustadas al formato modélico del documental divulgativo en espacios como La noche temática o Documentos TV, la cadena pública nacional Televisión Española

${ }^{1}$ Este trabajo se enmarca en el Proyecto de Investigación "La mirada televisiva. Evocación histórica y representación de la cultura política en España, 1977-2007”, financiado por la Comunidad Autónoma de Madrid y la Universidad Complutense (código de identificación: CCG08-UCM/HIS-4017). 
(TVE) viene emitiendo ininterrumpidamente desde septiembre de 2005 y hasta la fecha (finales del 2009) en horario de sobremesa, la telenovela Amar en tiempos revueltos ambientada en el período que va desde la Guerra Civil de 1936-1939 a la década de los cincuenta. En la primavera-verano de 2008 y 2009 este mismo canal programó La Señora, otra ficción seriada realizada por la misma productora que Amar en tiempos revueltos, pero localizada a inicios de los años veinte, durante la dictadura de Primo de Rivera. ${ }^{2}$

Este trabajo pretende poner de relieve alguna de estas claves de referencialidad histórica desde un enfoque general de corte cualitativo, atendiendo a algunos de los elementos centrales manejados en sus estrategias de evocación y verosimilitud sobre el pasado. Es decir, más allá de la disparidad de títulos o tramas particulares, nos interesa subrayar la existencia de un nexo común: el de la coherencia sobre las modalidades de representación histórica abordadas en muchas de estas series.

Un primer plano de interpretación sobre estos ejemplos ha de situarse, obviamente, en lógica comercial, en relación con las expectativas de rentabilidad ligadas a este tipo de productos. En general, todas ellas han obtenido cuotas de pantalla significativas. La audiencia lograda por Águila roja, de TVE 1 —emitida en la primavera de 2009— es una buena muestra de ello. Su último capítulo, programado el 21 de mayo, obtuvo un share de un $24,8 \%$ y sumó poco más de cinco millones de espectadores. Ambientada en el siglo XVII, combinaba una hibridación de citas de género de ascendente diverso: acción y aventuras, misterio, erotismo, relaciones familiares y

\footnotetext{
${ }^{2}$ Pueden recordarse diferentes producciones que han sido emitidas en horario prime time con claves de referencialidad histórica. TVE programó a lo largo del último trimestre de 2008 la décima temporada de la serie Cuéntame cómo pasó. En este caso se trata de una serie centrada en las peripecias cotidianas de una familia de clase media durante 1976, pocos meses después de la desaparición de Franco. Este último acontecimiento fue abordado también en el telefilm 20-N. Los últimos días de Franco, programado en noviembre de 2008 por la cadena privada Antena 3. A estos espacios cabría sumar dos producciones sobre el intento de golpe de estado de 1981, emitidas simultáneamente en febrero de 2009: El día más difícil del Rey (por TVE1) y 23F. Historia de una traición (Antena 3). También se ha abordado el terrorismo de ETA, recordando el secuestro y el asesinato del concejal Miguel Ángel Blanco en 1997 (en 48 horas, una miniserie programada en julio de 2008 por Antena 3) o el intento de asesinato del Rey Juan Carlos I en 1995 (en Una bala para el Rey, que fue emitida por la misma cadena en marzo de 2009). A ello habría que añadir la adaptación española de la serie británica Life on Mars ( $L a$ chica de ayer). O la dramatización biográfica de algún personaje popular en los años sesenta y setenta, como la actriz y cantante Pepa Flores, que se ha visto reencarnada en la miniserie Marisol, de Antena 3, en marzo de 2009. Cara a la nueva temporada abierta en septiembre de 2009, TVE ha emitido una nueva temporada de Cuéntame cómo pasó, y Antena 3 programará una miniserie de corte biográfico sobre la figura del que fuera Presidente del Gobierno, Adolfo Suárez. Ambas producciones tomaron como referencia el simbólico año de 1977, momento de la celebración de las primeras elecciones democráticas desde la Guerra Civil.
} 
sentimentales. A ojos del historiador profesional, Águila roja estaba plagada de anacronismos e incorrecciones documentales de bulto. Su tiempo histórico se descubre, pues, como desdibujado. Pero, al mismo tiempo, este mismo tiempo histórico vago y anacrónico se ha conformado como un parámetro coherente para otorgar credibilidad al relato. Proporcionaba un trasfondo verosímil lógico, donde cabía el despliegue de toda una batería de recursos orientados al entretenimiento y a la representación de valores culturales actuales, como la exaltación de la capacidad de autonomía femenina, la crítica al poder autoritario, el encumbramiento de la tolerancia familiar o el laicismo. Son claves que nos hablan de un mundo de valores de inicios del siglo XXI, y que sufren, por el contrario, una descontextualización radical al localizarse en el XVII. Desde este punto de vista, Águila roja sería un buen ejemplo de cómo la ficción histórica televisiva española actual ha sido capaz de configurar unos marcos básicos de evocación y reconocimiento, susceptibles de relacionarse de modo dialéctico con el presente y con el discurso historiográfico académico institucionalizado (Rosenstone, 2005:91-108).

Esta proposición de contenidos históricos no se ha constituido, sin embargo, un experimento radicalmente original. Entre las décadas de los años setenta y ochenta TVE desarrolló ya una dilatada línea de producciones emplazadas en tiempo pasado. Se trató de realizaciones que respondieron a unos estándares definidos: series de alto presupuesto, con una nítida conexión con la estética y la narratividad cinematográficas. Adaptaron textos literarios (como Fortunata y Jacinta, La barraca o Los Pazos de Ulloa) abordaron personajes del siglo XIX (como Mariana Pineda o Goya) o se interesaron por la crisis sociopolítica del primer tercio del siglo XX y por su expresión última, la Guerra Civil (por ejemplo, en Lorca, muerte de un poeta o en La forja de un rebelde). Más allá de su diversidad, se ha considerado que apelaron a un conjunto homogéneo de referentes simbólicos dramáticos y a un trasfondo discursivo común, compatibles con un imaginario colectivo asociado con valores como eran la libertad, la ciudadanía o la rehabilitación de los vencidos en la Guerra Civil (Palacio, 1999:145-150). Desde este punto de vista, se trataba de producciones que establecían un cierto revisionismo histórico, al tiempo que definían un engarce simbólico con la cultura política de corte democrático-institucionalizada tras la muerte de Franco.

No resulta exagerado considerar que estos relatos históricos presentaron entre sí un sentido análogo, ligado al empleo de unos códigos relativamente reconocibles. Este nivel de identificación debe valorarse, en primer lugar, en relación con el carácter de la televisión como instancia mediática hegemónica en la España del último tercio del siglo XX. Desde ahí, ha de subrayarse la importancia de su storytelling, en este caso vinculado a su capacidad para proponerse como "supernarrador social" de significaciones 
históricas. Este fenómeno fue coherente con el grado de universalización de la televisión, con su capacidad para mediatizar experiencias, y con su potencialidad para proponer una visualización generalizada de factores de reconocimiento y cohesión (Buonanno, 2006:99-105). A partir de ahí, se articularon y difundieron normativas sobre el pasado, coincidentes con episodios relevantes de la historia sociopolítica nacional: la revolución liberal y el constitucionalismo como seña característica del siglo XIX; la experiencia democrática de la II República y su conclusión dramática como consecuencia de la Guerra Civil y la dictadura franquista como eje del siglo XX. La ficción, entendida en términos de invención o imaginación, se revistió así de verosimilitud y legitimidad, en lógica con una praxis que evocaba raíces históricas comunes y criterios sobre el nosotros mismos, todo ello entendido como construcción de un sujeto histórico contemporáneo. Este referente se definió como estrategia de una tradición histórica compartida (Hobsbawm y Ranger, 1983) entendida como matriz susceptible de proyectar argumentaciones comunitarias afines al tiempo presente (Tsaliki, 1995:347-352).

A partir de este conjunto de elementos generales es desde donde ha de situarse la reflexión sobre el carácter homogéneo de las propuestas mencionadas al inicio de estas líneas. Esta oferta reciente se ha aproximado a marcos de emplazamiento originales, no abordados con anterioridad por la ficción televisiva. Ha evocado, como citas históricas concretas, a las figuras del General Franco o al Rey Juan Carlos, al terrorismo de ETA, al proceso de transición política desarrollado entre 1975 y 1981, al papel jugado en aquel contexto por la oposición de izquierdas o a la actitud del Ejército. Todas estas instancias se han localizado en unos parámetros específicos de articulación discursiva, coherentes con una idea dominante sobre el balance histórico, no sólo positivo, sino modélico, de la transición democrática española y a su legitimación actual. A ello se ha añadido el recurso reiterado a la nostalgia de la historia vivida por parte de un grueso de espectadores, al abordar episodios próximos en el tiempo y que podían ser identificados en primera persona.

Por otro lado, es obvio que la ficción histórica televisiva internacional ha propuesto desde los años sesenta relatos interesados en facilitar vías de interpretación a la audiencia. El caso español no ha sido ninguna excepción en este escenario. Tal y como ha señalado Edgerton (2001:2-6) cabe hablar de una historia popular televisiva, vertebrada mediante la intersección entre ejercicios de recuperación selectiva de hechos pretéritos, tratamiento dúctil del pasado, simplificación y condensación argumental y recurso, como espacio de mediación, a mecánicas de afirmación y familiaridad. Además, la televisión ha definido señas históricas de gran alcance, condicionadas por las dinámicas de transnacionalización de formatos, recursos retóricos o pautas de producción. Pero todos estos aspectos se han adecuado a los contextos 
particulares de recepción mediante una implicación con elementos temáticos o ambientales y con mecánicas de lectura de carácter específicamente local.

Por otro lado, es igualmente obvio que la producción reciente de la ficción histórica en España ha evidenciado toda una serie de enunciaciones temáticas y de focalización dirigidas hacia un mercado nacional, entendido éste como ámbito natural de consumo. Dicho extremo ayuda a problematizar la idea de la televisión como mera caja de resonancia de formatos transnacionales. Permite relacionarla, por el contrario, con la plasmación de ejercicios particularizados de visibilidad histórica, en relación lógica con el paradigma de la indigenización formulado por Buonanno (1999:54-69). En este sentido, la ficción española ha contextualizado la historia reciente en el marco de un proyecto discursivo que ha recreado claves propias del escenario español, de sus hitos decisivos o de ciertos usos y costumbres existentes en su historia social. Sin embargo, paralelamente ha trabajado con dos niveles diferenciados de referencialidad histórica, coherentes, a su vez, con plasmaciones distintas sobre cómo entender y reflejar empíricamente la noción de cultura sociopolítica nacional desde la televisión. ${ }^{3}$

Este fenómeno ha tenido implicaciones distintas. Ha representado, por una parte, un claro indicador en una política televisiva donde han coexistido cadenas con un distinto radio de presencia geográfica. El proceso de descentralización política desarrollado en España desde inicios de los años ochenta se ha constatado mediante la creación de este tipo de canales regionales. En segundo término, esta dualidad territorial ha neutralizado, en cierta forma, la distinción entre operadores televisivos por el mero hecho de que éstos fuesen públicos o privados, resaltando, por el contrario, la distinción ligada al factor territorialidad y a su ajuste con ámbitos socioculturales precisos de recepción. Todo ello se ha expresado en el recurso a niveles diferenciados de discursividad histórica, conviviendo así las ficciones que han operado con un radio aquilatado (la historia catalana, la historia vasca, la historia valenciana) junto a realizaciones que han manejado un trasfondo más genérico, identificable con la historia española. Sin embargo, este juego de particularismos no ha obviado las transferencias de claves temáticas o ideológicas o de estándares de producción. Así por ejemplo, Amar en tiempos revueltos ha conectado claramente con una telenovela catalana previa que ha servido de matriz (Temps de silenci) y Cuéntame cómo pasó ha supuesto un

\footnotetext{
${ }^{3}$ Ha de apuntarse al respecto la presencia de una versión sobre lo reciente español, encarnada en las cadenas generalistas nacionales TVE y Antena 3. Pero también una extensa tradición de evocaciones históricas sobre lo concreto regional, formulada desde los años noventa por canales públicos autonómicos, como los de Cataluña (TV3) el País Vasco (ETB) y, en menor medida, Andalucía (Canal Sur) o la Comunidad Valenciana (Canal Nou).
} 
José Carlos Rueda Laffond

claro modelo para una serie localizada en el contexto más cerrado de una pequeña localidad valenciana (L'alqueria blanca).

\section{CONSTRUYENDO UNA IMAGEN DE ENCUENTRO EN LA DEMOCRACIA}

Durante la transición a la democracia (1975-1982) la clase política española adoptó, en general, una actitud que prolongaba la importancia otorgada a la televisión por el poder franquista. El medio se concibió desde los años cincuenta como una herramienta privilegiada para la proposición de orientaciones gubernamentales y la vinculación entre televisión y política ha sido una constante conflictiva a lo largo del último tercio del siglo XX. ${ }^{4}$

La memoria retrospectiva inmediata sobre la transición ha corrido a cargo, inicialmente, de diversas producciones documentales. Entre ellas resaltaría una serie — La Transición, emitida inicialmente en 1995 por TVEque ha constituido un verdadero paradigma de evocación histórica televisiva. En ella se planteó un relato sobre el cambio político apoyado en una base argumental nítida: el papel jugado por diferentes personajes, como el Rey Juan Carlos, las elites reformistas procedentes del franquismo y, en menor medida, los líderes de los partidos mayoritarios de oposición de izquierda. Estos actores se definieron como los arquitectos indiscutidos en el diseño de un nuevo marco, caracterizado por la asimilación de principios participativos democráticos. Esta focalización sería compatible con la representación de la ciudadanía, cuyo protagonismo efectivo se limitaría, esencialmente, a evidenciar un respaldo tácito a las operaciones políticas desarrolladas desde el poder.

Hasta fecha reciente, la ficción televisiva no ha evocado el tardofranquismo y la transición democrática. El primer espacio de referencia para ambos contextos lo encontraríamos en Cuéntame cómo pasó, que viene siendo emitida desde septiembre de 2001, y en la actualidad (finales de 2009) desarrolla ya su undécima temporada. La serie ha construido su principal eje de continuidad a partir de un enfoque costumbrista sobre los Alcántara, una familia de clase media urbana que reside en una barriada periférica de Madrid. Cuéntame cómo pasó ha construido su argumento mediante la individualización de procesos de cambio. Su punto de referencia dramático ha sido el núcleo familiar, subrayando su capacidad para incorporar el bienestar material y el estatus simbólico ligado a la fase expansiva del desarrollismo económico (1962-1974). Como correlato, determinadas tendencias estructurales (la

\footnotetext{
${ }^{4}$ Este fenómeno ha definido una relación dialéctica con su hipotética naturaleza como servicio público. Ello sería extensible tanto a los canales públicos como privados y, respecto al canal público nacional TVE, puede rastrearse tanto durante las fases de gobierno centrista (19761982), socialista (1982-1996) o de centro-derecha (1996-2004). (Bustamante, 2006:59-200).
} 
emigración campo-ciudad, los procesos de urbanización, la escolarización masiva, la incorporación de la mujer al mundo laboral, la conciencia política y de género) han sido ejemplificadas a lo largo de sus diversas temporadas, mediante su sistemática personificación por medio del elenco de personajes (Rueda y Guerra, 2009:396-409).

Cuéntame cómo pasó ha construido un discurso sobre el cambio coherente con el formulado por La Transición. Antonio Alcántara (Imanol Arias), su protagonista, ha constatado unas actitudes de sentido común y racionalidad pragmática que evocarían, simbólicamente, a la otorgada por la serie documental a la ciudadanía española durante el proceso de transición a la democracia. De este modo, documental y ficción han trabajado con un prisma de coherencia en torno a ciertos valores estimados como axiomáticos: la existencia de una cultura social mayoritaria, básicamente apática y desmovilizada, ajustada a la presencia de la dictadura; la conciencia colectiva de su agotamiento institucional a raíz de la muerte de Franco y, finalmente, el apoyo social generalizado al proceso de desmontaje del entramado del régimen. En este sentido, la televisión española ha formulado un relato común desde dos planos dramáticos diferenciados: el que correspondería al discurso documental pedagógico y, con posterioridad, el referido a la representación ficcional del hecho histórico. Antonio Alcántara no ha sido presentado formando parte de los grupos de oposición política al franquismo, pero, tampoco, ha sido identificado con el discurso político oficial del régimen. Hasta 1975, Antonio se ha incrustado, en silencio aquiescente, en los dispositivos de control social y de bienestar material relativo del tardofranquismo. $^{5}$

Cuéntame cómo pasó puede ser percibido por el historiador como un producto emblemático de "historia mediática" (Martínez Gallego, 2009) ortodoxo y políticamente correcto, que ha propuesto una cierta visión edulcorada del último franquismo y de la transición, minimizando variables que pudieron jugar un papel activo en aquella coyuntura, como la movilización social o la eclosión del nacionalismo vasco y catalán (Bordería, 2005:54-62). Todo ello, como decimos, enlazaría con un marco historiográfico institucionalizado que ha tendido a sobrevalorar el protagonismo de las elites políticas —el Rey Juan Carlos, Adolfo Suárez, Torcuato FernándezMiranda o Santiago Carrillo - como factores decisivos en el reto de la superación no traumática del entramado heredado de la dictadura (Ysàs, 2008:101-102, en línea). No obstante, algunas aproximaciones a las pautas de recepción de la serie manifiestan otros extremos interesantes. Tal y como han

\footnotetext{
${ }^{5}$ Tras esa fecha participará en el desmontaje del aparato jurídico-legal franquista, presentándose como candidato al Congreso en las elecciones democráticas de junio de 1977.
} 
señalado Juan Francisco Gutiérrez Lozano (2006:443-444) y Mar Grandio (2008:146) Cuéntame cómo pasó se ha percibido como una propuesta histórica extraordinariamente verosímil gracias a su cuidado trabajo de escenografía y ambientación. En este sentido, las referencias concretas a determinados acontecimientos se habrían visto reforzadas, en términos de realismo, mediante esta evocación sobre los modos de vida, las costumbres, la importancia de los lazos familiares o la reconstrucción televisiva de una cultura material con una fuerte impregnación nostálgica. Puede afirmarse, por tanto, que frente a la historia política de hechos y acontecimientos —el eje en la serie La Transición - en Cuéntame cómo pasó se ha enfatizado la historia social, entendida como sustrato donde emplazar los códigos del entretenimiento y los mecanismos de reconocimiento espectatorial.

La exaltación de los actores políticos institucionales en coyunturas históricas críticas ha ocupado un protagonismo central en otras dos ficciones históricas recientes: 20-N. Los últimos días de Franco (R. Bodegas, con guión de A. Onetti y C. Silva, emitida en noviembre de 2008) y 23F. El día más difícil del Rey (S. Quer, con guión de H. Medina, emitida en febrero de 2009). La primera de ellas narra la enfermedad terminal de Franco, formulando una relación explícita entre aquellas semanas de 1975 y el inevitable colapso de su régimen. Como contrapunto a la figura del dictador, el relato proponía una caracterización antagónica del entonces Príncipe Juan Carlos. Frente al drama de la muerte que se desarrollaba intramuros de El Pardo, no es casual su emplazamiento en escenarios abiertos (los jardines del Palacio de la Zarzuela) coincidiendo con la representación de unas hipotéticas aproximaciones a los círculos de oposición antifranquista. La figura del futuro Rey era presentada, pues, de un modo nítido ante la audiencia desde un plano que no escapaba a una configuración presentista y, por tanto, abierta al empleo de anacronismos, subrayando su sentido como personaje despegado del círculo opaco de intereses que rodeó, en sus últimas horas, al Jefe del Estado. Desde ahí, 20- $N$ proponía pistas de reconocimiento decisivas sobre el tono radicalmente diferenciado que, frente a los usos de la dictadura, identificará su gestión una vez ascienda al trono. En esta lógica, se contrapusieron sin dobleces las nociones de pasado (guerra y dictadura) y futuro (democracia y reconciliación).

Esta caracterización ficcional de Juan Carlos I sería plenamente congruente con el enfoque establecido en 23-F. El día más difícil del Rey, donde también se ha manejado una perspectiva unívoca del monarca como impulsor y guardián de la democracia. En este caso cabe hablar, además, de un producto inserto en las coordenadas de una operación de competencia televisiva por la captación del mercado. Su emisión por TVE 1 coincidió con otra propuesta de corte temático idéntico (23F. Historia de una traición) emitida por Antena 3. Semejante simultaneidad se saldó con un claro respaldo 
espectatorial a la miniserie de TVE que llegó a obtener picos de audiencia de casi ocho millones, éxito que debe ponerse en relación con la orientación adoptada por una y otra. 23 F. El día más difícil del Rey optó por una estrategia argumental basada en la descripción detallada de las gestiones llevadas a cabo por Juan Carlos I ante la elite militar para desarticular el intento de golpe de Estado de 1981. Ahí estribaría su sentido como pedagogía histórica audiovisual, en el sentido de ilustrar la dimensión de lo conocido pero nunca visto como representación dramática.

En cambio, Historia de una traición apostó por un relato apoyado en la idea conspirativa y en la existencia de tramas oscuras que pudieron confluir en el levantamiento militar. En este sentido, la cadena pública estableció una narración mucho más canónica y reconocible, basada en una evocación a pequeña escala enmarcada en un escenario cerrado y con protagonistas diáfanos (el propio monarca, la Familia Real, su Secretario Sabino Fernández Campos). Este punto de vista dramático coincidía, a su vez, con una base documental generada desde inicios de los ochenta, nutrida con algunas investigaciones periodísticas que describieron minuciosamente aquellas horas, subrayando el papel del Rey como instancia decisiva a la hora de explicar el fracaso del golpe (Urbano, 1982:270-298).

La interrelación entre presentismo y mirada histórica televisiva sobre la realidad actual puede percibirse en la estrategia de efemérides desplegada en algunos ejemplos de producción informativa, por ejemplo coincidiendo con el vigésimo quinto aniversario de la instauración de la Monarquía, en 2000 (Humanes, 2003:39-57). Los últimos días de Franco y El día más difícil del Rey pueden ser estimados, también, como ejemplos singulares en esta panorámica de intermediación más amplia que estamos trazando, donde cabe una suerte de metanarrativa histórica televisiva sobre los factores de entorpecimiento en la normalización democrática (el propio Franco y los reductos autoritarios que, tras su muerte, subsistían en las Fuerzas Armadas). Frente a esa significación histórica dominante, ambas series presentaron, por primera vez, la figura del monarca codificada desde la ficción. Otro ejemplo de invisibilidad televisiva quebrado recientemente ha sido el del terrorismo de ETA, un elemento añadido más que, históricamente, puede ser estimado en términos de desestabilizador democrático durante el período de la transición. ${ }^{6}$

${ }^{6}$ El terrorismo fue abordado en diversos ejemplos de ficción histórica televisiva europea desde los años ochenta como Stammheim. Die Baader Meinhof-Grupe von gericht. R. Hauff (1986) o The Investigation: Inside a Terrorist Bombing, M. Beckham (1990). Y ETA, concretamente, ha sido objeto de una prolongada línea de evocación en el cine, si bien ésta ha ido oscilando la exaltación en la lucha antifranquista (Operación Ogro, G. Pontecorvo, 1979) a su papel ambiguo en el País Vasco (La muerte de Mikel 1983 y Días contados, 1993, ambas de I. Uribe), o reflejando su conversión en un reducto de intransigencia radical (Yoyes, H. Taberna, 
José Carlos Rueda Laffond

En este reacomodo en la pequeña pantalla se ha optado por una focalización sin dobleces, a partir de hechos recientes de gran impacto en la opinión pública. Así, en la miniserie 48 horas (M. Estudillo, 2008, con guión de L. Lorente) se narraba el secuestro y el asesinato de Miguel Ángel Blanco, concejal del Partido Popular en 1997. Aquel hecho fue abordado desde la lógica dramática de una inapelable cuenta atrás, dominada por el rechazo ciudadano generalizado, la unión de las fuerzas democráticas - entre ellas el Partido Nacionalista Vasco- y el consenso colectivo en torno al Gobierno de José María Aznar. Estos valores constituyeron las claves esenciales desarrolladas en el tratamiento periodístico de aquel suceso y nutrieron, también, la memoria de algunos documentales televisivos retrospectivos (como Miguel Ángel Blanco. El día que me mataron, de E. Blanco, 2006).

En Una bala para el Rey (realizada por P. Barrera) se abordaron los preparativos y la reacción policial subsiguiente para frustrar un atentado contra el Jefe del Estado, organizado durante sus vacaciones del verano en 1995. En este caso, el relato televisivo se enmarcó nítidamente en los códigos formales y semánticos del thriller realista. Y frente a 48 horas —-donde la figura de los terroristas García Gaztelu y Gallastegui se emplazaba en un segundo plano frente al protagonismo personal, familiar y social de la muerte de Blanco - contrapuso dos estereotipos modélicos: el del militante veterano (en la realidad, el activista de ETA Juan José Rego) capaz aun de expresar motivaciones políticas y el del joven terrorista ejecutor (Jorge García Sertucha) entendido como representante emblemático de la nueva ETA de los años noventa, caracterizada por la intolerancia, la frialdad y el desprecio moral. $^{7}$

\section{RECURSOS HISTÓRICOS Y POLÍTICAS DE PROMOCIÓN TELEVISIVA}

Las producciones citadas han operado, invariablemente, con un fuerte sentido de la realidad y del reconocimiento histórico cara a un grueso de la audiencia española, lo que tiende a matizar la idea simplificadora clásica de que sólo los espacios documentales son capaces de proveer al espectador de

2000; Todos estamos invitados, M. Gutiérrez Aragón, 2008). Sin embargo, no ha sido hasta 2008 — casi cincuenta años después de la creación de la organización — cuando ha migrado como temática a los terrenos de la ficción televisiva española, ya en el contexto de una democracia consolidada.

7 Semejante enfoque debe ser emplazado, no obstante, en un contexto de actualidad más amplio, en relación con variables como serían la percepción del fenómeno terrorista vasco tras los sucesos del 11 de septiembre de 2001 y el 11 de marzo de 2004, el paulatino reconocimiento público a las víctimas, o con el aislamiento y acoso policial de ETA tras el fracaso de las negociaciones políticas que tuvieron lugar entre ETA y el gobierno de Rodríguez Zapatero entre 2004 y 2007. 
claves objetivas de comprensión histórica (Niemi, 2006:22-23). En los casos considerados nos encontraríamos ante ejercicios diversos, interesados por articular una visión coherente de la historia reciente española desde los cánones de la ficción, independientemente de sus ingredientes de invención, subjetividad, eficacia interpretativa o simplificación simbólica. Complementariamente, tampoco debe perderse de vista la existencia de estrategias orientadas a la hibridación entre propuestas u formatos, algo que, en la relación entre documental divulgativo y ficción de ambientación histórica, se expresaría mediante la existencia de productos híbridos, que oscilarían entre el falso documental (o el documental ficcionalizado) y la ficción documentalizada. Este fenómeno se vería acompañado de la asimilación de otras influencias, procedentes, por ejemplo, de las claves formales o semánticas ensayadas por los formatos consolidados por la serialidad histórica anglosajona desde los años sesenta o setenta, o de géneros de fuerte carácter popular, como la telenovela.

Esta tendencia se ha evidenciado de modo notable, en el caso de Cuéntame cómo pasó que se ha situado en los estándares de género definidos, desde los años noventa, en el marco de la comedia familiar televisiva española. Mantiene, pues, obvios paralelismos con otros productos centrados en recrear la convivencia diaria familiar, como fueron las series Médico de familia o Los Serrano. Complementariamente, sus tramas han acusado fuertes influencias procedentes de los estándares de la telenovela. Pero, al mismo tiempo, ha asumido desde sus primeras entregas toda una batería de estrategias de evocación histórica: una cuidada ambientación, un exhaustivo trabajo de localización documental, unos efectos de posproducción que han permitido la copresencia de los personajes ficcionales e históricos, o un claro interés por ajustar las narrativas del tiempo diegético y el histórico.

Además, determinados acontecimientos han permitido la interrupción del flujo ficcional por medio de insertos documentales. La estructura de estos capítulos ha sido análoga: partían de las tramas serializadas y, desde ahí, incorporaban testimonios de periodistas o políticos, combinándolos con insertos de archivo o con pasajes de capítulos ya emitidos. Puede estimarse que este tipo de entregas han constituido ramificaciones de refuerzo, tendientes a insistir en la carga de verosimilitud que el espectador ha podido otorgar a la matriz ficcional. Al concluir la primera temporada, en junio de 2002, se emitió un episodio especial titulado Háblame de en el cual se combinaba un ejercicio de making-off y de síntesis expositiva documental, que permitía evidenciar diferentes estratos narrativos: el trabajo actoral y de realización de la serie, las tramas de ficción y las características estructurales que presentaba la sociedad española durante el tardofranquismo. 
José Carlos Rueda Laffond

Todo ello debe ser estimado en términos de proyección ante la audiencia del estatus de esta serie como narrativa histórica legitimada. Dicho estatus se ha asociado, a su vez, con una intensa política de promoción. En estas coordenadas, Cuéntame cómo pasó se ha presentado como un producto específico de calidad, enmarcado en una concepción de televisión de servicio público y en relación con su carácter como instancia social y como centro para la memoria colectiva. Estos aspectos se han presentado como factores de individualización de TVE frente al resto de operadores televisivos, tanto privados como autonómicos. La propia historia de TVE fue abordada, específicamente, en uno de estos capítulos de corte documental y el intenso potencial nostálgico de Cuéntame cómo pasó se ha visto amplificado gracias a diversos materiales de marketing. A su vez, desde la página web del programa también se ha ensalzado esta veta legitimadora de la ficción como vía de aproximación histórica, al insistirse en su conexión con la memoria sentimental colectiva de toda una época. En diciembre de 2008, coincidiendo con el cierre de su décima temporada, la serie presentaba una sección específica (“Así era España”) que incluía fragmentos de diversos programas procedentes del archivo de TVE, al tiempo que se reseñaba cómo algunos hechos singulares habían inspirado argumentos concretos (Humanes, 2009; en línea).

Este tipo de estrategias se han complementado con espacios de montaje, basados en la recuperación y emisión de materiales de archivo. Entre 2006 y 2007, en el contexto de las efemérides del cincuentenario de TVE, se produjeron varios de estos programas retrospectivos de corte documental ( $\mathrm{La}$ imagen de tu vida, Las 50 imágenes de nuestra vida y La tele de tu vida). La primera temporada de La imagen de tu vida constó de doce episodios e incluyó un total de seiscientos fragmentos de archivo y obtuvo una cuota media de audiencia de dos millones y medio de espectadores. Estos programas fueron presentados por un veterano periodista, Jesús Hermida. Su emisión se produjo en las noches de los jueves —en ocasiones tras Cuéntame cómo pasó- en una velada monográfica dedicada a una doble traducción de recuerdo televisivo: la evocada mediante la ficción seriada y la generada gracias a la redifusión de fragmentos informativos de hechos notorios acaecidos durante las últimas cinco décadas. Este sentido de TVE como herramienta para definir el estatus de acontecimiento histórico y su ligazón con la memoria colectiva se vio reforzado, además, mediante la incorporación de una sección estable en los noticiarios (Telediarios) de fin de semana. En ella se volvieron a recuperar fragmentos emitidos entre los años sesenta y la conclusión del siglo XX, adecuándolos a un formato de breve reportaje donde se aunaban la mirada al pasado, los recuerdos en primera persona y el 
contexto de la información en tiempo presente, propios de la naturaleza del noticiario donde se insertaban estos breves espacios.

Esta lógica de promoción ha tenido otras expresiones complementarias durante los últimos años. La serie 48 horas se presentó públicamente como un relato veraz, surgido de un trabajo de reconstrucción documental para lograr un "guión fiel a la realidad", posible gracias a la colaboración de la familia de Miguel Ángel Blanco (Las últimas 48 horas de Miguel Ángel Blanco, en línea). Argumentaciones similares se han planteado en otros casos, como en la telenovela de TVE Amar en tiempos revueltos, que también ha sido presentada como "un fiel retrato de la España de posguerra", fruto de un "riguroso y galardonado trabajo de documentación" (Amar en tiempos revueltos: un fiel retrato de la España de posguerra”, en línea). ${ }^{8}$

Amar en tiempos revueltos no ha sido la única exploración en los terrenos de la telenovela histórica en España. TVE programó también en horario de prime time nocturno en 2008 y 2009 el serial La Señora. En palabras de Virginia Yagüe (Televisión Española, 2008:8, en línea) autora de la idea y del argumento, esta serie pretendía "combinar romanticismo, épica y crónica histórica", ya que "nuestros personajes están enfrentados a sus pasiones, irremediablemente ligadas a la convulsa realidad de principios de siglo, que conduce a la inevitable lucha de clases”. El resultado fue un producto con una caracterización histórica surgida de mecanismos superficiales y banales, pero que incorporaba criterios análogos a la praxis de representación de Amar en tiempos revueltos, en aspectos como serían la evocación estereotipada de las tensiones políticas e ideológicas entre izquierda y derecha en la España del tercio central del siglo XX. En ambos casos se ha propuesto a la audiencia un proyecto explicativo construido por apelaciones de corte moral críticas con el conservadurismo y sus instituciones históricas (como la Iglesia o el Ejército). En el primer caso, rastreando las raíces del franquismo como actitud social y como universo de valores reaccionarios, latente ya en los años veinte; en Amar en tiempos revueltos,

\footnotetext{
${ }^{8}$ Respecto a esta serie se han analizado sus conexiones temáticas con el tiempo presente, resaltándose el juego de conexiones existentes entre su tipificación histórica general, el desarrollo de tramas y personajes y ciertos debates públicos suscitados entre 2004 y 2005, como la polémica sobre la Ley de la Memoria Histórica, la aprobación de la ley contra la violencia de género o el reciente reconocimiento del matrimonio homosexual en España (Galán Fajardo, en línea). El discurso de Amar en tiempos revueltos ha enlazado, además, con esa tradición formulada en las series de ficción de TVE de los años ochenta, interesadas por revisitar los años treinta y la Guerra Civil desde una óptica crítica contra el franquismo. A todo ello cabría añadir, tal y como se ha considerado en el texto, otros aspectos singulares, como las influencias transtextuales, procedentes de la telenovela latinoamericana y de la experiencia de producción de seriales en Cataluña, si bien adecuando sus marcas semánticas a un reconocimiento territorial amplio, definible como historia nacional española (Smith, 2008:7-8).
} 
como trasfondo institucionalizado de represión política o social y de agobiante rigorismo no exento de hipocresía y doble moral.

Podríamos situar en parámetros equiparables de reflexión histórica simplificada y descontextualizada a la serie de ficción Dos de Mayo. La libertad de una nación, si bien su trasfondo histórico e ideológico sería abiertamente disímil frente al propuesto en Amar en tiempos revueltos o en $\mathrm{La}$ Señora, esta última emitida en 2008, esta vez por la cadena pública regional Telemadrid. Su estructura argumental se ajustó, una vez más, a las reglas normativas de la telenovela y, tras la emisión de su primer episodio, se programó un documental de corte explicativo con el objetivo de definir un ejercicio de pedagogía, de legitimación del discurso ficcional y de reactualización de una imagen interesada de la guerra contra Francia de 1808-1814.

Con esta serie, la televisión madrileña asumió un cariz de plataforma discursiva para una ficción histórica donde se encuadraban problemáticas propias del tiempo presente. La producción planteaba una trama de índole coral, en la cual los personajes encarnaban el carácter simbólico del patriotismo nacional frente a las tropas francesas, subrayando específicos referentes españoles, como la lengua o la centralidad espacial (Madrid). De este modo, el serial constituyó un claro contrapunto a la política de producción de ficción desarrollada en Cataluña o el País Vasco, donde (desde los años ochenta) se ha ido materializando una singularización narrativa privativa mediante contenidos de claro cariz nacionalista (Castelló, 2008; 153-185; O’Donnell, 2007:37-54). Dos de Mayo exaltaba, así, a la nación española como sujeto histórico, a sus raíces de definición patriótica ("la lucha contra el francés”) y a un episodio que era abordado no en términos de oposición derecha/izquierda (como en La Señora o en Amar en tiempos revueltos) sino como referente aglutinante de unidad nacional. En este sentido, esta serie puede ser interpretada como un ejemplo de telenovela afín con el ideario político del Partido Popular y con su actitud ante los discursos particularistas del nacionalismo periférico vasco o catalán.

\section{CONCLUSIONES}

Este trabajo ha partido de algunas consideraciones generales acerca de la intersección entre ficción histórica televisiva, cultura y coyuntura política. La muerte de Franco y el proceso de transición a la democracia permitieron una lógica revisionista sobre la historia reciente desde la ficción televisiva española. Con la llegada al gobierno del Partido Socialista (1982) se estableció una política de producción que trasladó la Guerra Civil a la pequeña pantalla desde una óptica interpretativa abiertamente antifranquista. 
Con anterioridad, el siglo XIX fue presentado como escenario genérico donde podía situarse la cristalización de valores participativos ciudadanos. Esta perspectiva puede ser observada como reflejo de una lógica interesada por proyectar desde la televisión principios colectivos coherentes con el nuevo clima político definido a partir de 1975-1977.

Esta conexión entre coyuntura política y relato histórico televisivo puede observarse también en el contexto, mucho más inmediato, de 20082009. No es exclusivo, desde luego, del caso español. Y debe relacionarse con la complejidad que conlleva la interpretación sociocultural de la televisión como espacio para la producción y amplificación social de significaciones históricas. En este artículo se ha pretendido trazar algunas líneas en este sentido.

Un primer elemento esencial a destacar sería el referido a la relevancia de la televisión como espacio donde se produce la formulación de moldes de representación histórica a gran escala. No obstante, esta afirmación está trazada mediante un juego de factores e interacciones plurales, derivado de aspectos como serían la política de gestión y explotación del medio, los intereses comerciales, las estrategias de promoción, la adecuación de formatos, la propia praxis de la televisión como servicio público o la política de memoria mediática.

En cualquier caso, es posible resaltar la existencia de criterios de homogeneidad entre las diversas series de ficción aquí comentadas. Ello se constataría, por ejemplo, en el empleo de estándares de producción y realización relativamente equiparables. Las series mencionadas han respondido a criterios análogos de contratación entre canales y productoras especializadas en la confección de productos de ficción, y su objetivo último ha sido siempre el de la rentabilidad comercial. De este modo, la multiplicación de producciones históricas en la televisión española reciente puede ser valorada como una resultante implicada en los condicionantes de competencia programática, en particular, en el caso de la cadena pública nacional TVE y la privada Antena 3.

Por otra parte, nos encontramos ante producciones interesadas por un tiempo histórico cercano situado, por lo general, en la segunda mitad del siglo $\mathrm{XX}$ y que sería susceptible de un reconocimiento, siquiera vago, por parte del espectador. Estas realizaciones han incorporado rasgos equiparables de simplificación y condensación y no se han interesado directamente por la explicación de acontecimientos históricos, sino básicamente por la dramatización de los mismos y por su singularización mediante personajes o situaciones. El resultado ha sido, así, una categoría general de productos que pueden ser tipificados inicialmente bajo la etiqueta, sin duda imprecisa, de series de evocación histórica. 
El reconocimiento exige, además, la incorporación de claves presentistas, relacionadas con la cultura genérica de la audiencia, y con su potencial de descodificación e identificación. Este fenómeno ha podido resolverse mediante mecánicas de representación plagadas de anacronismos, tal y como se ha considerado en el caso de Águila roja, producción situada en un universo histórico muy alejado del tiempo presente (el siglo XVII). En tales coordenadas, el uso de estos anacronismos no le ha restado ni legitimidad dramática ni presumible verosimilitud histórica ante una audiencia no especializada. En otros muchos casos —Cuéntame cómo pasó sería, probablemente, el ejemplo modélico - las prácticas de ambientación y exposición de una representación presentada como realidad vivida y como espacio de nostalgia habrían coadyuvado a la neutralización aparente de estos mismos elementos presentistas a ojos del espectador. Esta neutralización constituiría un primer nivel donde situar la percepción de realismo histórico.

Las series comentadas en este trabajo han incorporado, además, otros aspectos que han podido reforzar dicha percepción. Por un lado, el que podríamos denominar como la homogeneidad discursiva, que, en esencia, ha configurado un parámetro general de ubicación significante de la historia reciente que ha pasado por encima de las diferencias existentes entre las diversas realizaciones.

Podemos estimar, por tanto, que ha existido una suerte de coherencia valorativa sobre diferentes períodos históricos, y que éstos han sido representados de modo relativamente unívoco. El primer franquismo ha sido abordado desde una óptica crítica que ha tendido a resaltar extremos como serían la represión de posguerra y la implicación de valores autoritarios en la vida social. Amar en tiempos revueltos ha expresado, así, un contexto plagado de dispositivos de control ideológico o de rigor moralista, vinculados con una cultura de poder de corte reaccionario e intolerante. Esta perspectiva enlazaría tanto con la experiencia discursiva practicada por la ficción histórica televisiva de los años ochenta como con alguna realización previa localizada en un contexto sociocultural aquilatado (Temps de Silenci). En cambio, el tardofranquismo ha sido abordado (por ejemplo, en Cuéntame como pasó) desde una óptica mucho más interesada por resaltar las dinámicas de cambio y de modernización social y económica. Ambas perspectivas disímiles sobre la etapa franquista serían coherentes, además, con lo formulado en otros ejemplos de evocación histórica cinematográfica centrados en los mismos períodos (Sánchez-Biosca, 2006:65-67).

La etapa de la transición a la democracia ha constituido un punto de referencia original para la ficción televisiva española. Esta fase histórica ha sido recreada desde dos ópticas: la propia de la historia "desde abajo" (Cuéntame cómo pasó) y la interesada en recrear determinados aconteci- 
mientos políticos de relieve (la muerte de Franco, el golpe de Estado del 23 de febrero de 1981). Pero, más allá de este distinto itinerario dramático, las diferentes producciones de ficción han propuesto un balance coherente, basado en cuatro ejes axiales: la idea de la incapacidad de reproducción institucional de la dictadura tras la desaparición física de su principal inspirador; la trascendencia del apoyo ciudadano a la dinámica de cambio político; el papel decisivo jugado por determinadas personas e instituciones, en particular por la figura de Juan Carlos I; y el carácter de los años 19751981 como período fundacional de la cultura política española actual. En este contexto, la ficción ha enfatizado una óptica legitimadora del sistema democrático, definiendo como antagonistas del mismo al golpismo militar reaccionario y a la presión terrorista.

Los relatos históricos han diseñado entonces una suerte de metanarrativa afín que ha sido susceptible de conectarse con una lógica metaficcional. Esta lógica se ha expresado mediante un juego tupido de afinidades interpretativas existentes entre el discurso documental y el de la ficción. Las relaciones de cercanía existentes entre Cuéntame cómo pasó y alguna serie documental representativa, como La Transición, serían un buen ejemplo de ello. A ello cabría sumar las tácticas de hibridación derivadas desde diversas ficciones. Tanto Cuéntame cómo pasó como Amar en tiempos revueltos o Dos de Mayo se han asociado con la emisión puntual de producciones de carácter documental, donde se ha combinado el discurso divulgativo y las tácticas de promoción de estos productos ficcionales, todo lo cual ha reflejado con nitidez una dinámica de intermediación entre formatos y lógicas televisivas en el ejercicio de la representación histórica, en coherencia con lo estudiado por Veyrat-Masson (2008).

Todo ello debe implicarse, a su vez, con el plano genérico de lo que se ha definido como la socialización institucionalizada del recuerdo (Burke, 2006:65-69) con los usos otorgados a la visibilidad e invisibilidad pública de la historia, o en relación con la capacidad de la televisión generalista para implicarse en la proyección de matrices de pasado legitimadoras respecto al tiempo presente. En definitiva: dicha socialización debe relacionarse con la capacidad de la ficción histórica televisiva para establecer unas determinadas configuraciones sobre la realidad histórica. De ahí que uno de los aspectos esenciales de este tipo de productos sea su potencialidad para emplazarse en la agenda de la actualidad como instrumentos de reactualización legitimadora ante la esfera pública. Este fenómeno ilustra con claridad el sentido funcional de la televisión como instancia en la producción social de la memoria histórica colectiva. Y complementariamente, este fenómeno nos arrastra, de nuevo, al principio de estas conclusiones: es decir, al terreno de la inter- 
José Carlos Rueda Laffond

sección que existe entre televisión, relato histórico, coyuntura política y cultura social.

\author{
Universidad Complutense de Madrid* \\ Facultad de Ciencias de la Información \\ Departamento de Historia de la Comunicación Social \\ Av. Complutense, s.n., C. P. 28013; Madrid (España) \\ jcrueda@pdi.ucm.es
}

\title{
BIBLIOGRAFÍA
}

“Amar en tiempos revueltos: un fiel retrato de la España de posguerra”. http://www.rtve.es/television/20080714/amar-tiempos-revueltos-fielretrato-espana-posguerra/115638.shtml.

(Consultado: 12 de marzo de 2009).

BORDERÍA, Enrique. "Los medios audiovisuales y la Historia. Memoria del franquismo y la Transición en la serie Cuéntame cómo pasó", en Aula de Historia Social 15 (2005):54-62.

BUONANNO, Milly. El drama televisivo. Identidad y contenidos sociales. Barcelona: Gedisa, 1999.

BUONANNO, Milly. L'età della televisione. Esperienze e teorie. Bari: Laterza, 2006.

BURKE, Peter. Formas de historia cultural. Madrid: Alianza, 2006.

BUSTAMANTE, Enrique. Radio y televisión en España. Historia de una asignatura pendiente de la democracia. Barcelona: Gedisa, 2006.

CASTELLÓ, Enric. Sèries de ficció i construcció nacional. Imaginat una Catalunya televisiva. Tarragona: Publicacions URV, 2008.

EDGERTON, Gary R. "Television as Historian. A Different Kind of History Altogether”, en VV. AA. Television Histories. Shaping Collective Memory in the Media Age. (Eds. G. R. Edgerton y P. C. Rollins). Kentucky: Kentucky University Press (2001):1-29.

GALÁN FAJARDO, Elena. "Las huellas del tiempo del autor en el discurso televisivo de la posguerra en España”, en Razón y Palabra. Narrativas Audiovisuales 56 (2007). http://www.razonypalabra.org.mx/anteriores/n56/egalan.html. (Consultado: 12 de noviembre de 2008).

GRANDIO, Mar. "La recepción de las series familiares contemporáneas. Los Serrano y Cuéntame cómo pasó”, en VV. AA. Series de televisión. El caso de Médico de familia, Cuéntame cómo pasó y Los Serrano (Ed. M. Medina). Madrid: Internacionales Universitarias (2008):133-163. 
GUTIÉRREZ LOZANO, Juan Francisco. La televisión en el recuerdo. La recepción de un mundo en blanco y negro en Andalucía. Málaga: Servicio de Publicaciones de la Universidad y RTVA, 2006.

HOBSBAWM, Eric y Ranger, Terence (Dirs.). The Invention of Tradition. Cambridge: Cambridge University Press, 1983.

HUMANES, María Luisa. "La reconstrucción del pasado en las noticias. La representación mediática del 25 aniversario de la muerte de Franco y la coronación de Juan Carlos I”, en Análisis 30 (2003):39-57.

"Inmaculada Benito: una adúltera en la España de Cuéntame". http://www.rtve.es/television/cuentame/historia/. (Consultado: 19 de febrero de 2009).

"Las últimas 48 horas de Miguel Ángel Blanco", en El Mundo. www.elmundo.es/elmundo/2008/06/30/television/1214838814.html. (Consultado: 1 de julio de 2008).

MARTÍNEZ GALLEGO, Francesc-Andreu. "Memoria social e historiografía mediática de la Transición”, en VII Congrés de l'Associació d'Historiadors de la Comunicació. 25 anys de llibertat d'expresió. Treballs de Comunicació, 20. (2005):34-54.

NIEMI, Robert. History in the Media. Film and Television. Santa Barbara: ABC-Clio, 2006.

O’DONNELL, Hugh. "High Drama, Low Key: Visual Aesthetics and Subject Positions in the Domestic Spanish Television Serial”, en Journal of Spanish Cultural Studies 8 (2007):37-54.

PALACIO, Manuel. "La historia en televisión", en Cuadernos de la Academia, 6 (1999):145-150.

ROSENSTONE, Robert. "La historia en imágenes/la historia en palabras: reflexiones sobre la posibilidad real de llevar la historia a la pantalla”, en Istor, 20 (2005):91-108.

RUEDA, José Carlos y Guerra, Amparo. “Televisión y nostalgia. The Wonder Years y Cuéntame cómo pasó”, en Revista Latina de Comunicación Social. 64 (2009):396-409.

SÁNCHEZ-BIOSCA, Vicente. Cine de historia, cine de memoria. La representación y sus límites. Madrid: Cátedra, 2006.

SMITH, Paul Julian. "Transnational Telenovela: The case of Amar en tiempos revueltos (Loving in Trobled Times)”, en Critical Studies in Television: Scholary Studies in Small Screen Fictions 3-2 (2008):4-18.

TELEVISIÓN ESPAÑOLA. Informa 2008. La Señora. Madrid: Dirección de Comunicación de RTVE, 5 de marzo de 2008. http://www.rtve.es/FRONT_SALA_PRENSA/Dossieres_de_prensa/. (Consultado: 20 de noviembre de 2008). 
José Carlos Rueda Laffond

TSALIKI, Lisa. "The Media and the Construction of an Imagined Community: the Role of Media Events on Greek Television”, en European Journal of Communication, 10:3 (1995):353-359.

URBANO, Pilar. Con la venia... Yo indagué el 23F. Barcelona: Argos Vergara, 1982.

VEYRAT-MASSON, Isabelle. Télévision et histoire, la confusion des genres: Docudramas, docufictions et fictions du reél. Paris and Louvain-laNeuve: De Boeck Université, 2008.

YSÁS, Pere. "Una nota sobre la crisi del franquisme i la transició a la democràcia”, en Historia Moderna i Contemporánea 3 (2005):101109. http://ddd.uab.es/pub/hmic/16964403n2005p101.pdf.

(Consultado: 28 de diciembre de 2008). 